\title{
Three-Dimensional Analysis of Craniofacial Shape in Obstructive Sleep Apnea Syndrome Using Geometric Morphometrics
}

\author{
Análisis Tridimensional de la Forma Craneofacial en el Síndrome de \\ Apnea Obstructiva del Sueño Mediante Morfometría Geométrica
}

\author{
Senem Turan Ozdemir ${ }^{1}$; Ilker Ercan²; Fatma Ezgi Can ${ }^{3,4}$; Gokhan Ocakoglu²; \\ Ezgi Demirdogen Cetinoglu ${ }^{5} \&$ Ahmet Ursavas ${ }^{5}$
}

OZDEMIR, S. T.; ERCAN, I.; CAN, F. E.; OCAKOGLU, G.; CETINOGLU, E. D. \& URSAVAS, A. Three-dimensional analysis of craniofacial shape in obstructive sleep apnea syndrome using geometric morphometrics. Int. J. Morphol., 37(1):338-343, 2019

SUMMARY: Craniofacial morphology is a risk factor for obstructive sleep apnea syndrome. The general aim of this study was to investigate the craniofacial shape differences in adults with and without obstructive sleep apnea syndrome, using geometric morphometric methods. A descriptive study conducted in 106 adult Turkish subjects, consisting of 50 patients with OSAS diagnosed by polysomnography and 56 non-OSAS controls. Three dimensional craniofacial scanning processes were performed on patient subjects on the same day as the PSG. Twelve standard craniofacial landmarks were collected from each subject's 3D craniofacial scan. Geometric morphometric analysis was used to compare the craniofacial shape differences between the OSAS and non-OSAS control groups. No statistically significant difference in terms of general shape in face shapes was found between the OSAS group and control group. However, local significance differences were found. There were significant differences between the groups in some of the interlandmark distances: $11 \%$ of the interlandmark distances were greater in OSAS patients, and $29 \%$ were greater in controls. Greater measured distances in OSAS are concentrated in the nasal region. In the control group, the difference is not concentrated in a specific region. Given the relationship of craniofacial structural alterations and sleep disordered breathing, we hypothesized that inter-landmark distance measurements in the craniofacial anatomy of patients might be predictive of OSA.

KEY WORDS: Obstructive sleep apnea; Craniofacial morphology; Geometric morphometry.

\section{INTRODUCTION}

Obstructive sleep apnea syndrome (OSAS) is a common clinical entitity that was formed by oxygen desaturation. The main symptom is daytime sleepiness during the day due to recurrent upper airway occlusion. OSAS is diagnosed by symptoms, clinical findings, physical examination, polysomnography (PSG), and imaging modalities. Polysomnography (PSG) is the "gold standard" for the diagnosis of OSAS.

The anatomical factors, mechanical factors, neuromuscular function, respiratory control instability, genetic factors are mentioned in OSAS etiology with a complex physiopathology (Patil et al., 2007; Albajalan et al., 2011; Mannarino et al., 2012). Obesity, male sex and advanced age, are the most significant known risk factors in OSAS. Craniofacial morphology is increasingly acknowledged as an important factor in the OSAS (Banabilh et al., 2010; Albajalan et al.; Sutherland et al., 2012; Dubey et al., 2015). Craniofacial morphology was investigated in OSAS patients by several methods such as 2-D lateral cephalometric analysis, two-dimensional photogrammetric analysis,3-D stereophotogrammetry. A large part of the work has been carried out with two dimensional cephalometric analyses and hard tissue worked. The studies using the method of three-dimensional scanning provide more detailed analysis, especially facial soft tissue features.

The statistical shape analysis has recently become more important in the medical and biological sciences (Ercan et al., 2012). Shape differences between geometric morphometric

\footnotetext{
${ }^{1}$ Department of Anatomy, Faculty of Medicine, Uludag University, Bursa, Turkey.

2 Department of Biostatistics, Faculty of Medicine, Uludag University, Bursa, Turkey.

${ }^{3}$ Department of Biostatistics and Medical Informatics, Faculty of Medicine, Izmir Katip Celebi University, Izmir, Turkey.

${ }^{4}$ Department of Biostatistics, Institute of Health Sciences, Uludag University, Bursa, Turkey.

${ }^{5}$ Department of Pulmonary Diseases and Tuberculosis, Faculty of Medicine, Uludag University, Bursa, Turkey.
} 
method and groups are being assessed with the average figure, local changes in addition to general shape differences can be introduced. A limited number of studies have examined craniofacial shape of subjects with OSAS using 3-D imaging with geometric morphometric methods (Banabilh et al., 2009, 2010).

The aim of this study was to compare the differences in the craniofacial shape of Turkish patients with OSAS and a non-OSAS control group.

\section{MATERIAL AND METHOD}

Subjects. This study was carried out with a total of 106 subjects including 50 OSAS 56 non-OSAS control groups. The mean age of 50 OSAS patients (31 male, 19 female) diagnosed with polysomnography was $50.79 \pm 9.07$. The control group consisted of 56 subjects, 30 male and 26 female, with a mean age of $42.42 \pm 7.44$. The non-OSAS control were subjects with simple snoring-diagnosed subjects after PSG $(\mathrm{AHI}<5)$. Each patient's age, sex, height and weight were recorded. The body mass index (BMI) was calculated from the patients height and weight in standart units $\left(\mathrm{kg} / \mathrm{m}^{2}\right)$. The median BMI of the OSAS patient group was $32.30 \mathrm{~kg} / \mathrm{m}^{2}(25.40-52)$ and the median BMI of the control group was $26.11 \mathrm{~kg} / \mathrm{m}^{2}(18.93-42.97)$.

Three-dimensional facial scanning procedure for evaluating facial soft tissue changes were performed on OSAS patients (applicants having sleep laboratory diagnosis due to complaints) on the same day as the polysomnography. All data collection were carried out by a single investigator. Ethical approval was obtained from the research and ethics committee of the Faculty of Medicine, Uludag University.
Collection of Three-Dimensional Craniofacial Landmarks. Following informed consent, three-dimensional craniofacial images were obtained using Artec 3D scanners for all subjects. Twelve standard homologous craniofacial soft tissue landmarks were collected from each subject's 3D facial scan using ARTEC 3D software program to obtain the $\mathrm{x}, \mathrm{y}, \mathrm{z}$ coordinates. These landmarks were chosen for their high reliability and ability to provide adequate facial shape. The landmarks were located on the face by the same investigator. The description of these landmarks are found in Table I and shown in Figure 1. Landmark data were used to determine differences of craniofacial shape between with OSAS and non-OSAS (control) groups. All data were subjected to duplicate digitization by the same imvestigator on two different occasions.

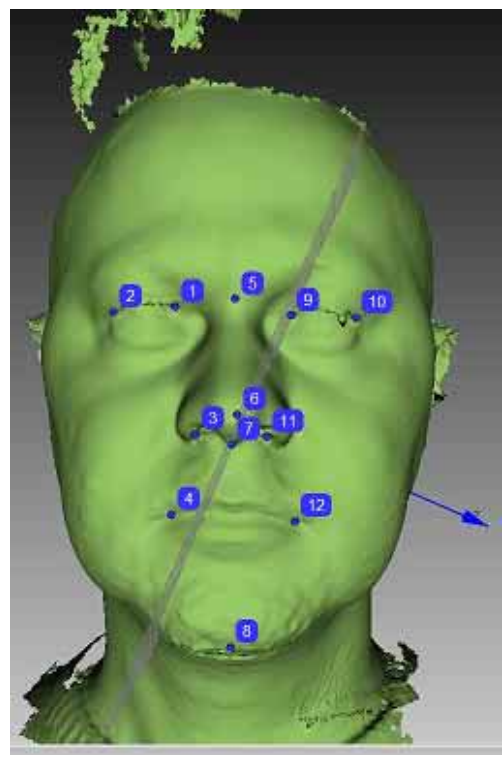

Fig. 1. Anthropometric landmarks on the face with 3D scanner.

$1,9=$ en,endocanthion;

2, 10=ex, exocanthion; $3,11=$ sbal, subalare; $4,12=$ ch, cheilion; $5=$ n, nasion; $6=$ prn, pronasale; $7=$ sn, subnasale; $8=$ gn, gnathion)

Table I. Anthropometric landmarks used in the study.

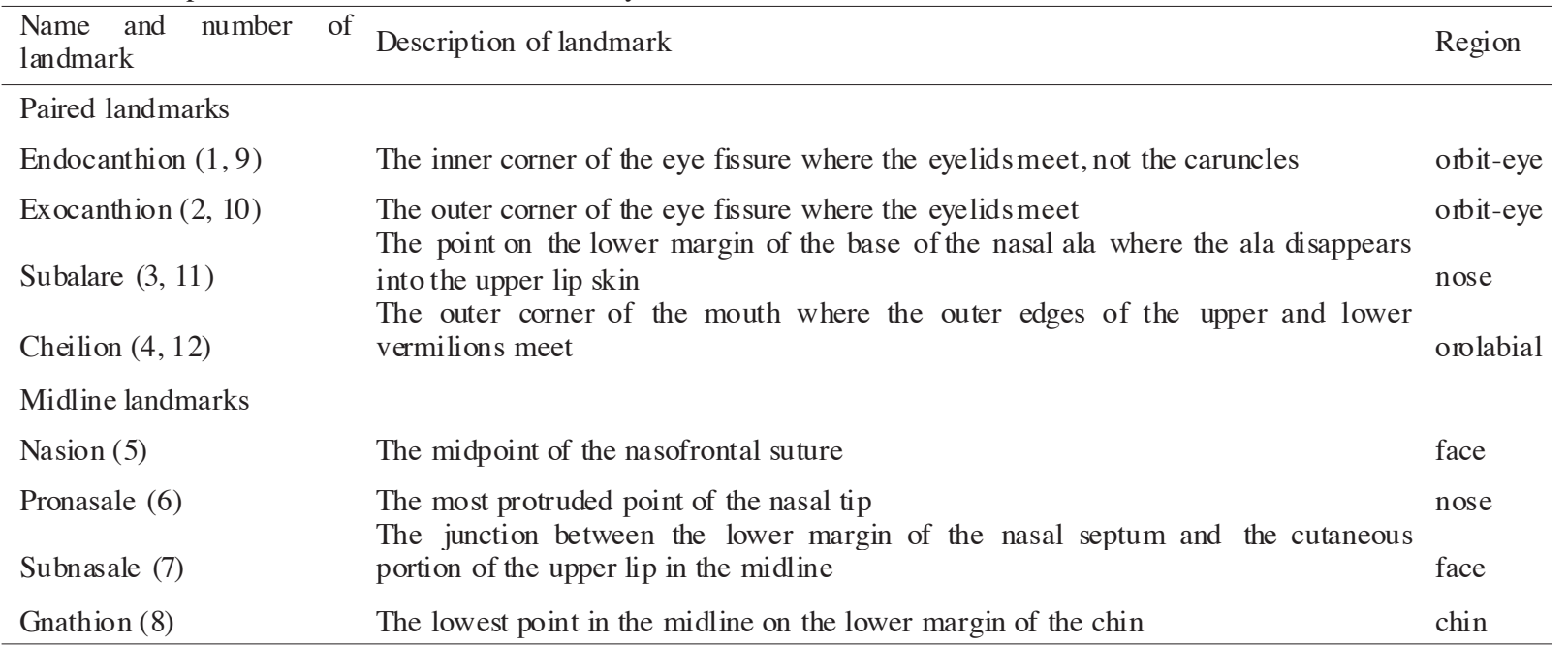


Statistical Analysis. Statistical shape analysis was performed for evaluation of facial morphology. In statistical shape analysis, generalized Procrustes analysis and EDMA II was used. Principal component analysis was applied to tangent coordinate which derived from Procrustes analysis. EDMA II analysis comparison of shapes and interlandmark differences. For EDMA II, we used the geometric means of the distances among landmarks as scaling factors and standardized the form difference matrix for each sample by dividing each entry by the appropriate scaling factor. A parametric bootstrap technique (Monte Carlo) was used to create 1000 resamples. We performed statistical tests on the null hypothesis of the equality of the shapes for subsets of landmarks and used confidence interval testing to evaluate the statistical significance of differences in individual linear distances (Cole \& Lele, 2002). Demographic characterictics were compared with independent samples t test, MannWhitney U test and Pearson chi-square test. In this study, the R 3.4 and PAST 3.0 software were used for the statistical analysis.

\section{RESULTS}

Inter-landmark reliability was found $\mathrm{G}=0.652$ in our study. As our study included three dimensional data, inter landmark reliability was found sufficient.
No statistically significant difference in terms of sex was found between the groups $(\mathrm{p}=0.318)$. However, statistically significant difference was found according to age and BMI $(\mathrm{p}<0.001 ; \mathrm{p}<0.001)$. The mean age of the OSAS patient group was 50.79 \pm 9.07 and the mean age of the control group was $40.59 \pm 7.44$. In the current study, the BMI was found to be significantly greater for the OSAS group compared to non-OSAS group. Using PCA, no statistically significant difference in terms of general shape in face shapes was found between the OSAS group and control group.

According to principal component analysis results, narrow range in the patients scatter were seen than controls (Fig. 2). In our study, craniofacial features of OSAS cases were more standard than controls (less varied). However local significance differences were found $(\mathrm{p}<0.05$; Table II). In the face, the $12(\mathrm{k})$ landmarks had $66((\mathrm{k}(\mathrm{k}-1)) / 2)$ interlandmark distances, which were statistically compared. There were significant differences between the groups in some of the interlandmark distances: $11 \%$ of the interlandmark distances were greater in OSAS patients, and $29 \%$ were greater in controls (Fig. 3). Greater measured distances in OSAS are concentrated in the nasal region (sbal-sn; pr-sn; sbal (r)-sn; sbal(l)-sn; pr-sbal (r); pr-sbal (l); ch-n). In the control group, the difference is not concentrated in a specific region. In the control group, subnasale-gnathion (sn-gn), nasion-gnathion (ngn), cheilion- cheilion (ch (r) -ch (l)), and the nasion-pronasale (n-prn) distances are greater (Fig. 3, Table II).

Table II. The inter-landmark distances found to be significantly different between OSAS and non-OSAS control.

Landmarks

The greater interlandmark distances in OSAS patients

3-7, 6-7, 4-5, 7-11, 6-11, 3-11, 3-6

The greater interlandmark distances in controls

$4-8,2-8,3-8,2-3,8-9,7-8,8-10,10-11$, $8-12,8-11,2-7,5-8,2-6,9-11,6-9,4-12,7-9,5-6,7-10$

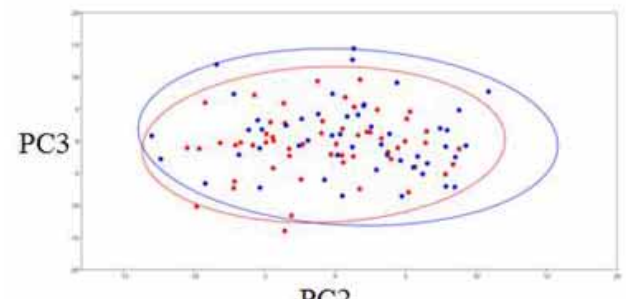

$\mathrm{PC} 2$

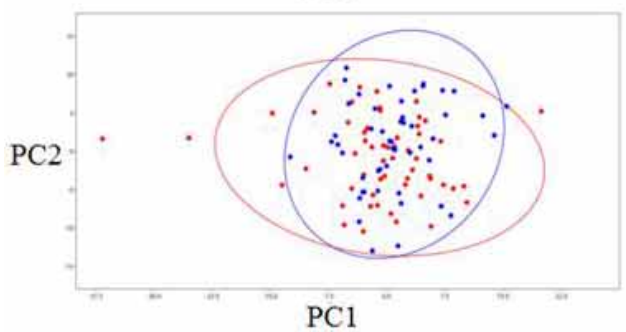

Fig. 2. Scatter graphs with $95 \%$ confidence ellipses and Principal Components Analysis results of controls (red dots) and OSAS patients (blue dots). A: OSAS subjects, B:non-OSAS(control) subjects.

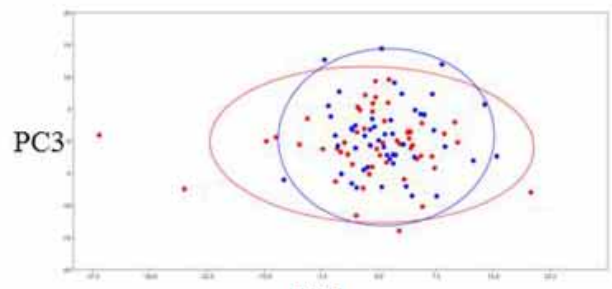

PC1

\begin{tabular}{|c|c|c|c|}
\hline PC & Eigenvalue & $\begin{array}{c}\text { \% Variance } \\
\text { explained }\end{array}$ & \% Cumulative \\
\hline 1 & 5164.3 & 26.60 & 26.60 \\
\hline 2 & 2971.4 & 15.31 & 41.91 \\
\hline 3 & 2078.9 & 10.71 & 52.62 \\
\hline
\end{tabular}



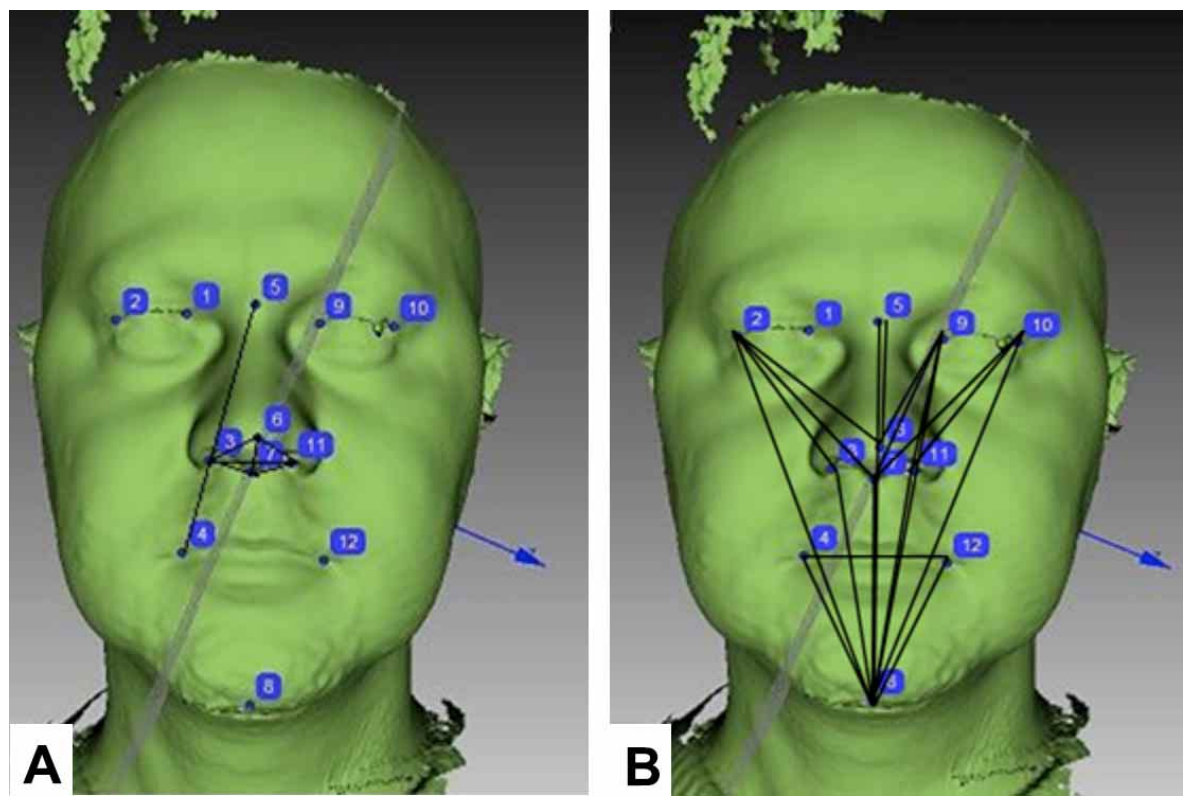

Fig. 3. A. The greater interlandmark distances in OSAS patients (3-7, 6-7, 4-5, 7-11, 6-11, 3-11, 3-6).

B. The greater interlandmark distances in controls $(4-8,2-8$, $3-8,2-3,8-9,7-8,8-10,10-11$, $8-12,8-11,2-7,5-8,2-6,9-11$, $6-9,4-12,7-9,5-6,7-10)$

\section{DISCUSSION}

Craniofacial morphology is increasingly recognized as an risk factor in OSA pathogenesis. Whether patients with OSAS have a certain prototype of face or not; whether the patients with a specific face shape are more prone to the development of OSAS or not (Lee et al., 2009a,b; Sutherland et al., 2016; Agha \& Johal, 2017), whether there is a correlation between the severity of the clinical manifestations of OSAS and the craniofacial morphology or not, are the researched topics (Bates \& McDonald, 2005; Costa E Sousa $\&$ dos Santos Gil, 2013). Although the full picture of the craniofacial hard and soft tissue patterns associated with the OSAS and its severity is a question still under investigation, mainly with respect to ethnic craniofacial differences (Albajalan et al.; Sutherland et al., 2014; Dubey et al.). Sutherland et al. (2012) indicated that understanding of ethnic differences in OSAS craniofacial phenotypes is important in the recognition, treatment and prevention of OSAS. Albajalan et al. indicated that since craniofacial features differ between ethnic populations, the specific characteristics of OSAS for each population should be investigated. This study demonstrates that 3D craniofacial shape differences between Turkish subjects with and without OSA can be identified with a statistical shape analysis technique.

Craniofacial soft tissue differences have been reported for patients of OSAS both in two dimensional photographic analysis and three-dimensional images (Lee et al., 2009a,b; Banabilh et al., 2009, 2010; Bruwier et al., 2016). Lee et al. (2009a) have found that face width, mandible width, intercanthal width and nose width metrics, are larger than the control group in their study, identifying craniofacial phenotypic characteristics of OSAS patients with $2 \mathrm{D}$ digital images. They have reported that eye width not previously reported, is a predictor of OSAS in addition to anatomical risk factors highlighted in literature such as face width, cervicomental angle, mandibular length. In another study focusing on the relationship between surface facial dimensions and upper airway structures in patients with OSAS, it was reported that the strongest correlation was demonstrated between the volume of the tongue and the width of midface and the lower face (Dempsey et al., 2002). Amra et al. (2015) reported that mandibular width was the most important index, which had a significant association with the OSAS severity. Banabilh et al. (2009) reported that craniofacial obesity in the bucco-submandibular regions is associated with OSAS, and may provide valuable screening information for the identification of patients with undiagnosed OSAS. We investigated the craniofacial region in this study by considering the mean shape and localized changes. While there was no significant difference between the OSAS subjects and controls in terms of general craniofacial features, some significant local differences were seen. In all, possible linear distances were used for the craniofacial shape analysis to evaluate the differences between the two groups (OSAS and non-OSAS). Seven interlandmark distance found larger (greater) in OSAS group than the non-OSAS. On the other hand, nineteen interlandmark distance found larger (greater) in non-OSAS 
group. There were significant differences between the groups in some of the interlandmark distances: $11 \%$ of the interlandmark distances were greater in OSAS patients, and $29 \%$ were greater in controls (Fig. 3). Greater measured distances in OSAS are concentrated (collected) in the nasal region (sbal-sn; pr-sn; sbal (r)-sn; sbal(l)-sn; pr-sbal (r); prsbal (1); ch-n). Particularly noteworthy among the 19 interlandmark distances measured in the control group are subnasale-gnathion (sn-gn) used as a prognathic maxillary profile indicator, nasion-gnathion ( $\mathrm{n}-\mathrm{gn})$ distance corresponding to face height, cheilion- cheilion (ch (r) -ch (1)) distance corresponding to mouth width and nasion-pronasale (n-prn) distance tatistical shape analysis compares body forms by using specific landmarks determined by anatomical (n-prn) distance corresponding to nasion bridge lenght (Fig. 3, Table II). Subnasale-gnathion distance corresponds to the distance of the lower facial height. Lower facial height is one of the important parameters for normal anatomical structure of the oral cavity. It was found that there were significant differences between lower face height between patients with OSA and control group. The higher value of the subnasale to gnathion distance recorded in control groups shows that prognathic maxillary profile is more prevalent in control subjects than OSAS. Yilmaz \& Akcaalan (2017) found that the lower facial height distance was higher in the non-OSAS control group for Turkish population and their emphasized that the increase of this distance allows more oxygen transmission capacity by increasing the oral cavity. Also, the facial height distance was found higher in the control group in our study. In the literature, in most studies, distances of anterior facial height and anterior lower facial height were found to be higher in OSAS than in controls. On the other hand Albajalan et al. reported that no significant differences were found in lower anterior, posterior, or total face height between the OSAS and control groups. In this study, the mouth width and nasal bridge length distances were also found greater in the control group.

On the other hand, in OSAS, nostril floor width distance (right and left side) was found greater than control group. Length of the baseline of the nose (columella deviation length = sn-prn) was also found more in the OSAS group.

However, we can still emphasize that OSA is a multifactorial clinical entitiy, the etiology of OSAS is too diverse and complex to be explained by a simple relationship established between craniofacial morphology (size and shape) and the development of the disease.

\section{ACKNOWLEDGMENTS}

This work was supported by the Uludag University Research Foundation (Grant No. OUAP(T)-2013/1).
OZDEMIR, S. T.; ERCAN, I.; CAN, F. E.; OCAKOGLU, G.; CETINOGLU, E. D. \& URSAVAS, A. Análisis tridimensional de la forma craneofacial en el síndrome de apnea obstructiva del sueño mediante morfometría geométrica. Int. J. Morphol., $37(1): 338-343,2019$.

RESUMEN: La morfología craneofacial es un factor de riesgo para el síndrome de apnea obstructiva del sueño. El objetivo general de este estudio fue investigar las diferencias de forma craneofacial en adultos con y sin síndrome de apnea obstructiva del sueño utilizando métodos morfométricos geométricos. Un estudio descriptivo realizado en 106 sujetos turcos adultos, de 50 pacientes con SAOS diagnosticados mediante polisomnografía y 56 controles no SAOS. El proceso de escaneo craneofacial tridimensional se realizó en pacientes sujetos el mismo día que el PSG. Se recogieron doce puntos de referencia craneofaciales estándar del escaneo craneofacial 3D de cada sujeto. Se usó el análisis morfométrico geométrico para comparar las diferencias de forma craneofacial entre los grupos de control SAOS y no SAOS. No se encontraron diferencias estadísticamente significativas en términos de forma general en las formas de la cara entre el grupo SAOS y el grupo control. Sin embargo, se encontraron diferencias de significación local. Hubo diferencias significativas entre los grupos en algunas de las distancias interlandmark: el $11 \%$ de las distancias interlandmark fueron mayores en los pacientes con SAOS y el $29 \%$ en los controles. Las mayores distancias medidas en SAOS se concentran en la región nasal. En el grupo de control, la diferencia no se concentra en una región específica. Dada la relación de las alteraciones estructurales craneofaciales y la alteración de la respiración durante el sueño, planteamos la hipótesis de que las mediciones de distancias inter-hito en la anatomía craneofacial de los pacientes podrían ser predictivas de la SAOS.

PALABRAS CLAVE: Apnea obstructiva del sueño; Morfología craneofacial; Morfometría geométrica.

\section{REFERENCES}

Agha, B. \& Johal, A. Facial phenotype in obstructive sleep apnea-hypopnea syndrome: a systematic review and meta-analysis. J. Sleep Res., 26(2):122-31, 2017

Albajalan, O. B.; Samsudin, A. R. \& Hassan, R. Craniofacial morphology of Malay patients with obstructive sleep apnoea. Eur. J. Orthod., 33(5):509-14, 2011

Amra, B.; Peimanfar, A.; Abdi, E.; Akbari, M.; Penzel, T.; Fietze, I. \& Golshan H. Relationship between craniofacial photographic analysis and severity of obstructive sleep apnea/hypopnea syndrome in Iranian patients. J. Res. Med. Sci., 20(1):62-5, 2015.

Banabilh, S. M.; Samsudin, A. R.; Suzina, A. H. \& Dinsuhaimi, S. Facial profile shape, malocclusion and palatal morphology in Malay obstructive sleep apnea patients. Angle Orthod., 80(1):37-42, 2010.

Banabilh, S. M.; Suzina, A. H.; Dinsuhaimi, S.; Samsudin, A. R. \& Singh, G. D. Craniofacial obesity in patients with obstructive sleep apnea. Sleep Breath., 13(1):19-24, 2009.

Bates, C. J. \& McDonald, J. P. The relationship between severity of obstructive sleep apnoea/hypopnoea syndrome (OSAHS) and lateral cephalometric radiograph values: a clinical diagnostic tool. Surgeon, 3(5):338-46, 2005. 
Bruwier, A.; Poirrier, R.; Albert, A.; Maes, N.; Limme, M.; Charavet, C.; Milicevic, M.; Raskin, S. \& Poirrier, A. L. Three-dimensional analysis of craniofacial bones and soft tissues in obstructive sleep apnea using cone beam computed tomography. Int. Orthod., 14(4):449-61, 2016.

Cole, T. \& Lele, S. Bootstrap-based methods for comparing morphological integration patterns. Abstracts of AAPA Poster and Podium Presentations. Am. J. Phys. Anthropol., 117(Suppl. 34):55, 2002.

Costa E Sousa, R. A. \& dos Santos Gil, N. A. Craniofacial skeletal architecture and obstructive sleep apnoea syndrome severity. $J$. Craniomaxillofac. Surg., 41(8):740-6, 2013.

Dempsey, J. A.; Skatrud, J. B.; Jacques, A. J.; Ewanowski, S. J.; Woodson, B. T.; Hanson, P. R. \& Goodman, B. Anatomic determinants of sleepdisordered breathing across the spectrum of clinical and nonclinical male subjects. Chest, 122(3):840-51, 2002.

Dubey, A.; Upadhyay, S.; Mathur, S.; Kant, S.; Singh, B. P. \& Makwana, R. Comparative evaluation of craniofacial anthropometric measurements in Indian adult patients with and without obstructive sleep apnea: A pilot study. J. Indian. Prosthodont. Soc., 15(4):331-6, 2015.

Ercan, I.; Ocakoglu, G.; Sigirli, D. \& Ozkaya, G. Statistical shape analysis and usage in medical sciences: review. Turk. Klin. J. Biostat., 4(1):2735, 2012.

Lee, R. W.; Chan, A. S.; Grunstein, R. R. \& Cistulli, P. A. Craniofacial phenotyping in obstructive sleep apnea--a novel quantitative photographic approach. Sleep, 32(1):37-45, 2009a

Lee, R. W.; Petocz, P.; Prvan, T.; Chan, A. S.; Grunstein, R. R. \& Cistulli, P. A. Prediction of obstructive sleep apnea with craniofacial photographic analysis. Sleep, 32(1):46-52, 2009b.

Mannarino, M. R.; Di Filippo, F. \& Pirro, M. Obstructive sleep apnea syndrome. Eur. J. Intern. Med., 23(7):586-93, 2012.

Patil, S. P.; Schneider, H.; Schwartz, A. R. \& Smith, P. L. Adult obstructive sleep apnea: pathophysiology and diagnosis. Chest, 132(1):325-37, 2007.

Sutherland, K.; Lee, R. W. \& Cistulli, P. A. Obesity and craniofacial structure as risk factors for obstructive sleep apnoea: impact of ethnicity. Respirology, 17(2):213-22, 2012.

Sutherland, K.; Lee, R. W.; Petocz, P.; Chan, T. O.; Ng, S.; Hui, D. S. \& Cistulli, P. A. Craniofacial phenotyping for prediction of obstructive sleep apnoea in a Chinese population. Respirology, 21(6):1118-25, 2016.

Sutherland, K.; Schwab, R. J.; Maislin, G.; Lee, R. W.; Benedikstdsottir, B.; Pack, A. I.; Gislason, T.; Juliusson, S. \& Cistulli, P. A. Facial phenotyping by quantitative photography reflects craniofacial morphology measured on magnetic resonance imaging in Icelandic sleep apnea patients. Sleep, 37(5):959-68, 2014.

Yilmaz, A. \& Akcaalan, M. What can anthropometric measurements tell us about obstructive sleep apnoea? Folia. Morphol. (Warsz), 76(2):3016, 2017.

\author{
Corresponding author: \\ Senem Turan Ozdemir M.D. \\ Department of Anatomy \\ Faculty of Medicine \\ Uludag University \\ 16059 Bursa/ \\ TURKEY
}

E mail: senem@uludag.edu.tr

Received: 26-07-2018

Accepted: 21-12-2018 